\title{
When the Truth Is Not Too Hard to Handle
}

\section{An Event-Related Potential Study on the Pragmatics of Negation}

\author{
Mante S. Nieuwland ${ }^{1,2}$ and Gina R. Kuperberg ${ }^{1,2,3}$ \\ ${ }^{1}$ Tufts University, ${ }^{2}$ Massachusetts General Hospital/Massachusetts Institute of Technology/Harvard Medical School \\ Athinoula A. Martinos Center for Biomedical Imaging, and ${ }^{3}$ Massachusetts General Hospital
}

\begin{abstract}
Our brains rapidly map incoming language onto what we hold to be true. Yet there are claims that such integration and verification processes are delayed in sentences containing negation words like not. However, studies have often confounded whether a statement is true and whether it is a natural thing to say during normal communication. In an event-related potential (ERP) experiment, we aimed to disentangle effects of truth value and pragmatic licensing on the comprehension of affirmative and negated real-world statements. As in affirmative sentences, false words elicited a larger N400 ERP than did true words in pragmatically licensed negated sentences (e.g., "In moderation, drinking red wine isn't bad/good..."), whereas true and false words elicited similar responses in unlicensed negated sentences (e.g., "A baby bunny's fur isn't very hard/soft. . "). These results suggest that negation poses no principled obstacle for readers to immediately relate incoming words to what they hold to be true.
\end{abstract}

To make sense of everyday language, it is essential for people to map what is said onto what they hold to be true about the world. This verification process is carried out routinely and almost immediately as a message unfolds over time (e.g., Fischler, Childers, Achariyapaopan, \& Perry, 1985; Hagoort, Hald, Bastiaansen, \& Petersson, 2004; see also Singer, 2006), with false statements being more difficult to evaluate than true statements. Yet, a large body of psycholinguistic evidence points

Address correspondence to Mante S. Nieuwland, Department of Psychology, Tufts University, 490 Boston Ave., Medford, MA 02155, e-mail: mante@nmr.mgh.harvard.edu. to a possible exception: in sentences that convey a negated message, it may actually be harder to evaluate true statements than to evaluate false statements ("A robin is not a tree/bird"; Fischler, Bloom, Childers, Roucos, \& Perry, 1983). According to nonincremental, two-step theories of negation, evaluating "A robin is not a tree" is difficult because people suppose the false inner proposition ("A robin is a tree") before applying the negation term to compute truth value (e.g., Carpenter \& Just, 1975; Clark \& Clark, 1977; Kintsch, 1974; for a review, see Kaup, Lüdtke, \& Zwaan, 2007; Singer, 2006).

Negation processing has also been studied using eventrelated potentials (ERPs; Fischler et al., 1983; Hald, Kutas, Urbach, \& Pahrhizkari, 2005; Kounios \& Holcomb, 1992; Lüdtke, Friedrich, De Filippis \& Kaup, 2008), which can provide qualitative information about language processing well in advance of (and without the principled need for) an explicit behavioral response. Those studies have focused on the N400, a negative voltage deflection in the ERP that indexes early semantic processing costs (Kutas \& Hillyard, 1980, 1984), regardless of whether they are aspects of semantic retrieval or integration (e.g., Kutas, Van Petten, \& Kluender, 2006; see also Coulson \& Federmeier, in press; Van Berkum, in press). Although, in affirmative statements, the N400 is modulated by real-world knowledge (e.g., Hagoort et al., 2004), previous studies suggest that this is not true of negated statements: In the example above, tree elicits a larger N400 than bird in both affirmative and negated sentences (e.g., Fischler et al., 1983). In accordance with a two-step account, these results suggest that nonpropositional semantic processes precede the decision processes that compute sentence truth value (e.g., Fischler et al., 1983; Hald et al., 2005; Kounios \& Holcomb, 1992; Lüdtke et al., 2008). 
TABLE 1

Example Sentences With Truth-Value and Naturalness Ratings for Each Condition

\begin{tabular}{|c|c|c|c|}
\hline \multirow[b]{2}{*}{ Condition } & \multirow[b]{2}{*}{ Example sentence } & \multicolumn{2}{|c|}{ Mean rating } \\
\hline & & Truth value & Naturalness \\
\hline \multicolumn{4}{|c|}{ Pragmatically licensed negation } \\
\hline True-affirmative & With proper equipment, scuba-diving is very safe and often good fun. & $4.47(0.46)$ & $4.02(0.54)$ \\
\hline True-negated & With proper equipment, scuba-diving isn't very dangerous and often good fun. & $4.52(0.40)$ & $3.90(0.44)$ \\
\hline False-affirmative & With proper equipment, scuba-diving is very dangerous and often good fun. & $1.37(0.40)$ & $1.38(0.37)$ \\
\hline False-negated & With proper equipment, scuba-diving isn't very safe and often good fun. & $1.39(0.38)$ & $1.36(0.37)$ \\
\hline \multicolumn{4}{|c|}{ Pragmatically unlicensed negation } \\
\hline True-affirmative & Bulletproof vests are very safe and used worldwide for security. & $4.75(0.31)$ & $4.02(0.66)$ \\
\hline True-negated & Bulletproof vests aren't very dangerous and used worldwide for security. & $4.77(0.31)$ & $1.93(0.39)$ \\
\hline False-affirmative & Bulletproof vests are very dangerous and used worldwide for security. & $1.19(0.25)$ & $1.13(0.19)$ \\
\hline False-negated & Bulletproof vests aren’t very safe and used worldwide for security. & $1.25(0.32)$ & $1.26(0.44)$ \\
\hline
\end{tabular}

Note. Standard deviations are given in parentheses. Critical words are underlined. For truth value, $1=$ false, $5=$ true; for naturalness, $1=u n n a t u r a l$, $5=$ natural .

Although a two-step theory of negation processing can account for much of the data, it seems hard to reconcile with people's common and almost effortless use of negation in everyday life (e.g., Givon, 1978; Horn, 1989). In fact, the available results might also be explained by taking into account the pragmatics of negation: People normally use negation to reject what plausibly may have been true (for example, earlier statements, exceptions, and plausible misconceptions, e.g., "A whale is not a fish"; see Wason, 1965). In contrast, denying something that makes no sense to begin with (e.g., "A robin is not a tree") violates the default assumptions that people have about speakers communicating rationally and efficiently. People expect a speaker's messages to be both true and informative (the so-called conversational maxims; Grice, 1975; Sperber \& Wilson, 1995). Indeed, difficulties associated with negation are diminished under pragmatic licensing conditions (e.g., Glenberg, Robertson, Jansen, \& Johnson-Glenberg, 1999; Johnson-Laird \& Tridgell, 1972; Wason, 1965). However, such findings are relatively sparse (see Kaup et al., 2007). Moreover, all results concerning the early stages of comprehending real-world statements suggest that negation is not used incrementally (see Lüdtke et al., 2008, for review). As pointed out by Kutas et al. (2006), however, ERP researchers have thus far only examined the comprehension of pragmatically unlicensed negation.
In the current ERP study, we attempted to settle this longstanding dispute on the temporal interplay between pragmatic context, negation, and world knowledge. We measured ERP responses while participants read statements containing midsentence critical words that rendered the statement true or false. In contrast to earlier studies, we did not require ERP participants to explicitly verify the sentences, but rather to simply read for comprehension. We contrasted the two-step and pragmatic account of negation by fully crossing negation and truth value in sentences where negation was either pragmatically licensed or unlicensed. Pragmatic licensing was independently assessed in a naturalness-rating pretest (see Tables 1 and 2), which allowed us to separate true-negated sentences into those where the critical word was relatively informative ("With proper equipment, scuba-diving isn't very dangerous") versus underinformative or trivial ("Bulletproof vests aren't very dangerous").

According to a two-step theory of negation processing, early semantic processes disregard the negation term. Therefore, this account predicts a larger N400 for false than for true words in affirmative statements, but a reverse effect in negated statements, regardless of whether negation is pragmatically licensed or unlicensed. According to a pragmatic account, however, negation terms are immediately incorporated during sentence

TABLE 2

Mean Position, Frequency, and Length of Critical Words

\begin{tabular}{lccc}
\hline \hline Condition & $\begin{array}{c}\text { Position in } \\
\text { sentence }\end{array}$ & $\begin{array}{c}\text { Log- } \\
\text { frequency }\end{array}$ & $\begin{array}{c}\text { Length in } \\
\text { letters }\end{array}$ \\
\hline $\begin{array}{l}\text { Pragmatically licensed negation } \\
\quad \text { True-affirmative and false-negated }\end{array}$ & 7.4 & & \\
$\quad \begin{array}{l}\text { True-negated and false-affirmative } \\
\text { Pragmatically unlicensed negation }\end{array}$ & 7.4 & 1.45 & 6.37 \\
$\quad \begin{array}{l}\text { True-affirmative and false-negated } \\
\text { True-negated and false-affirmative }\end{array}$ & 7.0 & 1.79 & 6.32 \\
\hline \hline
\end{tabular}


comprehension, and early semantic processes are modulated by how well the resulting meaning maps onto real-world knowledge and by our pragmatic knowledge of what is an informative versus a trivial thing to say. This account thus predicts a larger N400 for false words than for true words in both affirmative and pragmatically licensed negation statements, but not necessarily in unlicensed negation statements.

\section{METHOD}

\section{Development and Pretest of Materials}

We constructed 320 sentence quadruplets, each with two complementary predicates yielding opposite truth values in affirmative and negated sentences. Negated sentences were identical to affirmative sentences except for the negation term (e.g., an additional or contracted adverb like is not or isn't, or the adverb never). Most critical words were preceded by adverbs (e.g., very) or auxiliary verbs (e.g., wouldn't be). At least three words followed the critical words before the sentence ended.

To determine whether sentence fragments (truncated after the critical word) were, on average, regarded as true or false and as natural or unnatural, we conducted a rating pretest. We created eight counterbalanced lists of pseudorandomized sentences using similar procedures as for the ERP experiment (see below). Thirty Tufts students (mean age $=20.2$ years; 8 males, 22 females) each rated one list. For each sentence, they first decided whether its literal meaning was true $(1=$ false, $5=$ true $)$, and second, whether it constituted a natural thing for somebody to say and mean in a real conversation $(1=$ unnatural, $5=$ natural). Participants were made aware that sentences could be literally true but unnatural, and were instructed to rate false sentences as unnatural and skip any sentences they were unable to verify.

Based on the truth-value ratings, we excluded quadruplets containing true sentences rated below 3 , false sentences rated over 3 , or sentences that were skipped by more than two participants. Based on the naturalness ratings of the true-negated version, we then selected and categorized the 120 most natural and 120 most unnatural quadruplets as pragmatically licensed and unlicensed, respectively. The pragmatically licensed and unlicensed sentences were similarly rated for truth value across conditions, but critically differed in the naturalness rating of the true-negated sentences (see Table 1; see www.nmr.mgh.harvard. edu/kuperberglab/materials.htm for additional examples).

For the ERP experiment, we created four counterbalanced lists so that each sentence appeared in only one condition per list, but in all conditions equally often across lists. Within each list, items were pseudorandomly mixed with 120 filler sentences to limit the succession of identical sentence types and to maximize the distance between identical critical words (critical words appeared maximally three times per list, but generally at least twice) while matching trial types on average list position.

\section{ERP Experiment}

\section{Participants}

Twenty-eight right-handed Tufts students (9 males, 19 females; mean age $=20.7$ years) gave written informed consent. All were monolingual English speakers, and none had neurological or psychiatric disorders.

\section{Procedure}

ERP participants silently read sentences, presented wordby-word and centered on a computer monitor, while minimizing eye movements and blinks. To parallel natural reading times (Legge, Ahn, Klitz, \& Luebker, 1997), all words were presented using a variable presentation procedure. Word duration in milliseconds was computed as (number of letters $\times 27$ ) +187 , with a 10-letter maximum, and an additional $500 \mathrm{~ms}$ for sentencefinal words. All interword intervals were $121 \mathrm{~ms}$. Following final words, a blank screen was presented for $1,000 \mathrm{~ms}$, followed by either a fixation mark or a green-colored word and subsequent fixation mark. Sixty green words were pseudorandomly distributed following fillers and experimental sentences. Participants indicated by button-press whether these words were conceptually related to the preceding sentence (30 words required a "yes" response; e.g., flute following "Mozart was a musical child prodigy"). This ensured that participants paid attention to sentence content. At the fixation mark, subjects could blink and self-pace on to the next sentence. Participants were given seven short breaks. Total time-on-task was approximately $60 \mathrm{~min}$.

\section{Electroencephalogram Recording}

The electroencephalogram (EEG) was recorded from 29 standard scalp electrodes (referenced to the left mastoid; 2 additional electro-oculogram electrodes), amplified (band-pass filtered at $0.01-40 \mathrm{~Hz}$ ), and digitized at $200 \mathrm{~Hz}$. Impedance was kept below $5 \mathrm{kOhm}$ for EEG electrodes. Before off-line averaging, single-trial waveforms were automatically screened for amplifier blocking and muscle, blink, and eye movement artifacts over 650-ms epochs (starting $50 \mathrm{~ms}$ before critical word onset). Four participants were excluded due to excessive artifacts (mean trial loss $>35 \%$ ). For the remaining 24 participants, average ERPs (normalized by subtraction to a 50-ms prestimulus baseline) were computed over artifact-free trials for critical words in all conditions (mean trial loss across conditions = $10 \%$, range $=8-12 \%$ ).

\section{RESULTS}

Critical words elicited larger (more negative) N400s in the pragmatically licensed false-affirmative and false-negated sentences compared to true-affirmative and true-negated sentences, whereas they elicited larger N400s in the unlicensed false-affirmative, false-negated, and true-negated sentences compared to the true-affirmative sentences (see Fig. 1a). N400 effects in both licensed and unlicensed sentences dissipated 
True $\{$ Affirmative With proper equipment, scuba-diving is very safe...

Bulletproof vests are very safe... False $\begin{cases}\text { Affirmative } & \text { With proper equipment, scuba-diving isn't very dangerous... } \\ \text { Negated } & \text { With proper equipment, scuba-diving is very dangerous... }\end{cases}$

Bulletproof vests aren't very dangerous..

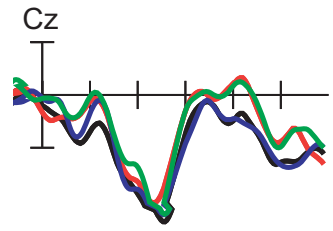

Bulletproof vests are very dangerous...

Bulletproof vests aren't very safe...

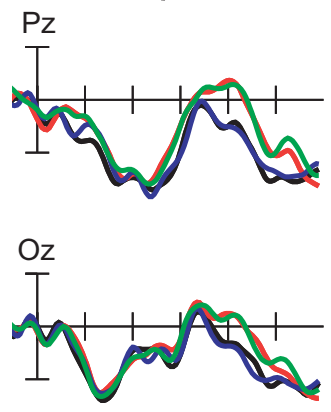

False Minus True (300-450 ms)
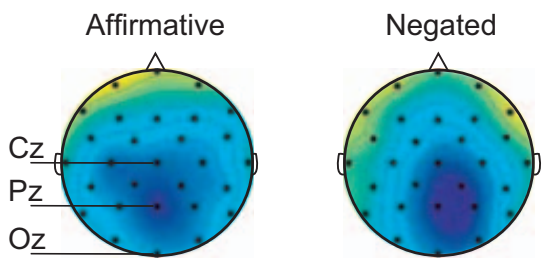

b

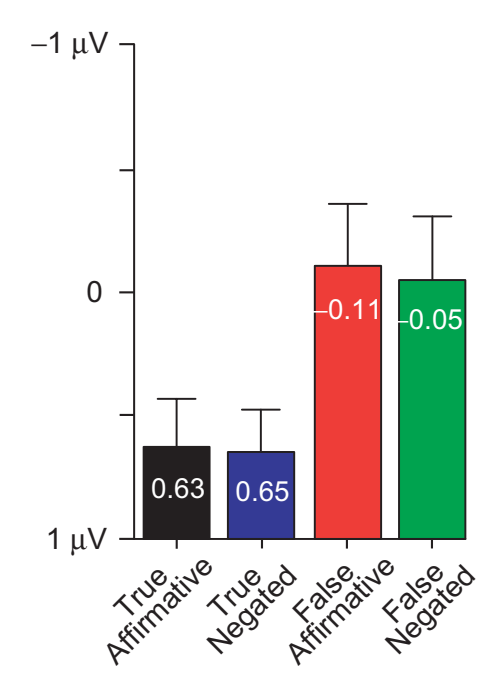

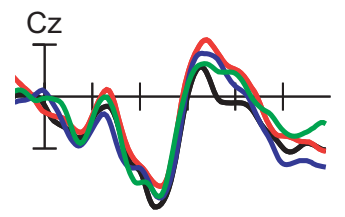
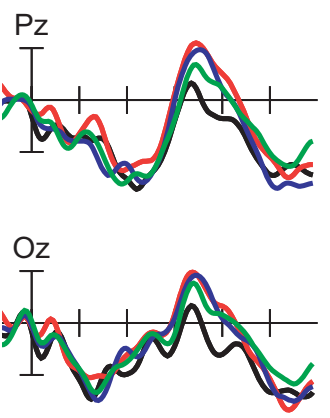

False Minus True (300-450 ms)

Affirmative

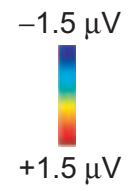

Negated

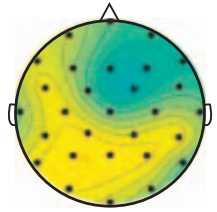

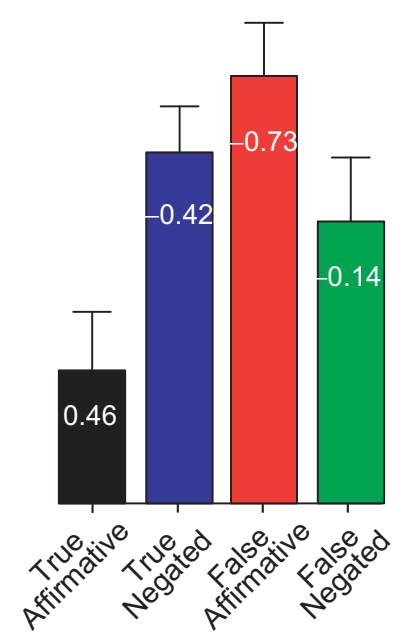

Fig. 1. Event-related potentials (ERPs) and mean ERP values in the time window that was used for statistical analysis. The graphs in (a) show the grand-average ERP waveforms elicited by critical words (CWs; underlined) in all eight conditions at electrode locations $\mathrm{Cz}, \mathrm{Pz}$, and $\mathrm{Oz}$. Results are presented separately for pragmatically licensed negation (left) and pragmatically unlicensed negation (right). In each of these conditions, stimuli consisted of affirmative statements and negative statements that were either true or false (examples are provided above the graphs). Scalp distributions of the relevant mean difference effects (false minus true sentences) in the 300- to 450-ms analysis window are given below the graphs. The graphs in (b) show mean ERP values (error bars show $1 S E$ ) in the 300- to 450-ms analysis window averaged over all 12 posterior electrodes. Results for pragmatically licensed negation (left) and pragmatically unlicensed negation (right) are shown. 
well before $500 \mathrm{~ms}$ after critical word onset, and had a typical posterior distribution. An initial 2 (pragmatics: licensed, unlicensed) $\times 2$ (truth value: true, false) $\times 2$ (negation: affirmative, negated) $\times 2$ (distribution: anterior, posterior) repeated measures analysis of variance (ANOVA) using mean amplitude in the 300- to 450-ms time window revealed an interaction between truth value and distribution, $F(1,23)=5.02, p_{\text {rep }}=.9$, $\left.\eta_{p}{ }^{2}=.179\right)$, reflecting larger N400 modulations at posterior electrodes. To gain maximal power, all further tests examined N400 ERP responses (300-450 ms) averaged over all 12 posterior electrodes (Pz, Oz, CP1/2, CP5/6, P3/4, P7/8, O1/2); see Figure $1 \mathrm{~b}$ for the resulting mean values.

A 2 (pragmatics) $\times 2$ (truth value $) \times 2$ (negation) three-way repeated measures ANOVA revealed an interaction of pragmatics, truth value, and negation, $F(1,23)=6.01, p_{\text {rep }}=.923$, $\eta_{p}{ }^{2}=.207$. $^{1}$ This interaction effect was parsed by conducting two 2 (truth value) $\times 2$ (negation) ANOVAs on the licensed and unlicensed sentences separately. In the licensed sentences, false critical words elicited a larger N400 component than true critical words, $F(1,23)=16.46, p_{\text {rep }}=.986, \eta_{p}{ }^{2}=.417$, but there was no interaction between truth value and negation, $F(1$, $23)=0.012, p_{\text {rep }}=.166, \eta_{p}{ }^{2}=.001$. In the unlicensed sentences, there was no main effect of truth value, $F(1,23)=3.20$, $p_{\text {rep }}=.832, \eta_{p}{ }^{2}=.122$, whereas there was an interaction between truth value and negation, $F(1,23)=17.16, p_{\text {rep }}>$ $.9863, \eta_{p}^{2}=.427$, that arose because false words elicited a larger $\mathrm{N} 400$ than true words in affirmative sentences, $F(1,23)=$ 15.32, $p_{\text {rep }}=.986, \eta_{p}{ }^{2}=.4$, but not in negated sentences, $F(1,23)=0.78, p_{\text {rep }}=.581, \eta_{p}^{2}=.033$.

\section{DISCUSSION}

We contrasted two competing accounts of negation processing by examining neural activity while participants read affirmative and negated sentences that varied in truth value and pragmatic licensing. As in affirmative sentences, false words elicited a larger N400 than true words when negation was pragmatically licensed. True words in unlicensed negation statements, however, elicited similarly increased N400 responses as false words. Our results are at odds with a two-step account of negation processing (e.g., Carpenter \& Just, 1975; Fischler et al., 1983; Kintsch, 1974), and instead suggest that negation is incrementally incorporated to construct sentence meaning. Because pragmatically licensed negation had no effect whatsoever on the N400 responses to true and false sentences, our results suggest that there are no additional semantic processing costs inherently associated with negation (see also Johnson-Laird \& Tridgell, 1972; Wason, 1965).

Our results also suggest that incoming words incur an immediate semantic processing cost, as indexed by the N400 (Kutas \& Hillyard, 1980, 1984), that depends not only on how

\footnotetext{
${ }^{1}$ There was no three-way interaction in the adjoining windows from 150 through $300 \mathrm{~ms}, F(1,23)=0.82, p_{\text {rep }}=.589, \eta_{p}^{2}=.034$, and from 450 through $600 \mathrm{~ms}, F(1,23)=1.11, p_{\text {rep }}=.642, \eta_{p}{ }^{2}=.046$.
}

well the resultant sentence meaning corresponds to real-world knowledge (cf. Hagoort et al., 2004), but also on whether this meaning is informative or, instead, trivial. We take the processing costs associated with trivially true utterances as reflecting the processing consequences of a violation of pragmatic communicational principles (e.g., Grice, 1975; Sperber \& Wilson, 1995). Following contexts such as "Bulletproof vests aren't very ....," it is most common to encounter a word that is both true and relatively informative (e.g., comfortable or cheap) instead of something trivially true (e.g., dangerous or fluffy). Therefore, we interpret our N400 findings as reflecting a close interaction between the evolving message-meaning with both real-world and pragmatic knowledge. This pragmatic knowledge might influence word-by-word integration (e.g., Brown, Hagoort, \& Kutas, 2000) or contribute to building up contextuallysupported expectancies about what upcoming words are likely to be encountered (e.g., DeLong, Urbach, \& Kutas, 2005; Federmeier, 2007; Van Berkum, in press).

Clearly, default pragmatic assumptions that addressees have about speakers communicating rationally and efficiently are sometimes violated in everyday communication without the message failing to get through (e.g., in the case of irony). However, even such "acceptable" violations are generally associated with semantic processing costs (Cornejo et al., 2007; see also Coulson, 2004). Although our pragmatically licensed negation sentences were rated as natural for a speaker to say and mean (i.e., ruling out an irony interpretation), some of the unlicensed negation sentences could well have been interpreted as ironic (e.g., "Donald Trump isn't very poor ...").

Although we demonstrated that false words and underinformative true words can incur similar semantic processing costs, earlier studies reported larger N400 responses to underinformative true words than to false words. Semantic-associative priming differences between critical words were probably larger in earlier studies (e.g., robin-bird/tree; Fischler et al., 1983) than in our study (e.g., bulletproof vests-safe/dangerous), which may partly account for the discrepancy if the initial semantic response in earlier studies was dominated by such "low-level" semantic relationships (see Ledoux, Camblin, Swaab, \& Gordon, 2006, for a review). However, several methodological differences further compromise a more direct comparison, including differences in critical word antonymy and sentence position, stimulus presentation rate and repetition, and verification task. Thus, we cannot rule out that negation is indeed processed in two stages under certain circumstances (see Lüdtke et al., 2008), and any account of the observed discrepancies across studies is necessarily tentative.

In sum, our results clearly suggest that negation poses no principled obstacle to incremental, high-level language comprehension. In other words, relating incoming words to our realworld knowledge is not necessarily more difficult in negated than in affirmative sentences, as long as negation is used to convey a pragmatically sound message. 
Acknowledgments - We are very grateful to Marta Kutas, Tali Ditman, and two anonymous reviewers for helpful comments. This research was supported by a Netherlands Organization for Scientific Research Rubicon grant (to M.S.N.) and by National Institute of Mental Health Grant NIMH-R01-MH071635 (to G.R.K.).

\section{REFERENCES}

Brown, C.M., Hagoort, P., \& Kutas, M. (2000). Postlexical integration processes in language comprehension: Evidence from brainimaging research. In M.S. Gazzaniga (Ed.), The cognitive neurosciences (2nd ed., pp. 881-895). Cambridge, MA: MIT Press.

Carpenter, P.A., \& Just, M.A. (1975). Sentence comprehension: A psycholinguistic processing model of verification. Psychological Review, 82, 45-73.

Clark, H.H., \& Clark, E.V. (1977). Psychology and language. New York: Harcourt Brace Jovanovich.

Cornejo, C., Simonetti, F., Aldunate, N., Ibáñez, A., López, V., \& Melloni, L. (2007). Electrophysiological evidence of different interpretative strategies in irony comprehension. Journal of Psycholinguistic Research, 36, 411-430.

Coulson, S. (2004). Electrophysiology and pragmatic language comprehension. In I. Noveck \& D. Sperber (Eds.), Experimental pragmatics (pp. 187-206). San Diego, CA: Palgrave Macmillan.

Coulson, S., \& Federmeier, K.D. (in press). Words in context: ERPs and the lexical/postlexical distinction. Journal of Psycholinguistic Research.

Delong, K.A., Urbach, T.P., \& Kutas, M. (2005). Probabilistic word pre-activation during language comprehension inferred from electrical brain activity. Nature Neuroscience, $8,1117-1121$.

Federmeier, K.D. (2007). Thinking ahead: The role and roots of prediction in language comprehension. Psychophysiology, 44, 491505.

Fischler, I., Bloom, P., Childers, D., Roucos, S., \& Perry, N. (1983). Brain potentials related to stages of sentence verification. Psychophysiology, 20, 400-409.

Fischler, I., Childers, D.G., Achariyapaopan, T., \& Perry, N.W. (1985). Brain potentials during sentence verification: Automatic aspects of comprehension. Biological Psychology, 21, 83-105.

Givón, T. (1978). Negation in language: Pragmatics, function, ontology. In P. Cole (Ed.), Syntax and semantics 9: Pragmatics (pp. 69-112). New York: Academic.

Glenberg, A.M., Robertson, D.A., Jansen, J.L., \& Johnson-Glenberg, M.C. (1999). Not propositions. Journal of Cognitive Systems Research, 1, 19-33.

Grice, P. (1975). Logic and conversation. In P. Cole \& J.L. Morgan (Eds.), Syntax and semantics 3: Speech acts (pp. 41-58). New York: Seminar.

Hagoort, P., Hald, L., Bastiaansen, M., \& Petersson, K.M. (2004). Integration of word meaning and world knowledge in language comprehension. Science, 304, 438-441.

Hald, L., Kutas, M., Urbach, T.P., \& Pahrhizkari, B. (2005, April). The N400 is not a brainwave: Negation and the N400 effects for true and false sentences. Poster presented at the annual meeting of the Cognitive Neuroscience Society, New York.

Horn, L. (1989). A natural history of negation. Chicago: University of Chicago Press.

Johnson-Laird, P.N., \& Tridgell, J. (1972). When negation is easier than affirmation. Quarterly Journal of Experimental Psychology, 24, 87-91.

Kaup, B., Zwaan, R.A., \& Lüdtke, J. (2007). The experiential view of language comprehension: How is negated text information represented? In F. Schmalhofer \& C.A. Perfetti (Eds.), Higher level language processes in the brain: Inference and comprehension processes (pp. 255-288). Mahwah, NJ: Erlbaum.

Kintsch, W. (1974). The representation of meaning in memory. Hillsdale, NJ: Erlbaum.

Kounios, J., \& Holcomb, P. (1992). Structure and process in semantic memory: Evidence from event-related brain potentials and reaction-times. Journal of Experimental Psychology: General, 121, 459-479.

Kutas, M., \& Hillyard, S.A. (1980). Reading senseless sentences: Brain potentials reflect semantic incongruity. Science, 207, 203205.

Kutas, M., \& Hillyard, S.A. (1984). Brain potentials during reading reflect word expectancy and semantic association. Nature, 307, 161-163.

Kutas, M., Van Petten, C., \& Kluender, R. (2006). Psycholinguistics electrified II: 1994-2005. In M. Traxler \& M.A. Gernsbacher (Eds.), Handbook of psycholinguistics (2nd ed., pp. 659-724). New York: Elsevier.

Ledoux, K., Camblin, C.C., Swaab, T.Y., \& Gordon, P.C. (2006). Reading words in discourse: The modulation of lexical priming effects by message-level context. Behavioral and Cognitive Neuroscience Reviews, 5, 107-127.

Legge, G.E., Ahn, S.J., Klitz, T.S., \& Luebker, A. (1997). Psychophysics of reading-XVI. The visual span in normal and low vision. Vision Research, 37, 1999-2010.

Lüdtke, J., Friedrich, C.K., De Filippis, M., \& Kaup, B. (2008). ERP correlates of negation in a sentence-picture-verification paradigm. Journal of Cognitive Neuroscience, 20, 1355-1370.

Singer, M. (2006). Verification of text ideas during reading. Journal of Memory and Language, 54, 574-591.

Sperber, D., \& Wilson, D. (1995). Relevance: Communication and cognition. Oxford, England: Blackwell.

Van Berkum, J.J.A. (in press). The neuropragmatics of "simple" utterance comprehension: An ERP review. In U. Sauerland \& K. Yatsushiro (Eds.), Semantic and pragmatic: From experiment to theory. Houndsmills, England: Palgrave Macmillan.

Wason, P. (1965). The contexts of plausible denial. Journal of Verbal Learning and Verbal Behavior, 4, 7-11.

(RECEIVED 12/5/07; REVISION ACCEPTED 6/6/08) 